\title{
The Geostationary Carbon Process Mapper
}

\author{
Richard Key, Stanley Sander, Annmarie Eldering, Charles Miller, Christian Frankenberg, \\ Vijay Natraj, David Rider, Jean-Francois Blavier, Dmitriy Bekker, Yen-Hung Wu \\ Jet Propulsion Laboratory, California Institute of Technology \\ 4800 Oak Grove Dr. \\ Pasadena, CA 91109 \\ 818-354-3060 \\ Corresponding author: Richard.Key@jpl.nasa.gov
}

\begin{abstract}
The Geostationary Carbon Process Mapper (GCPM) is an earth science mission to measure key atmospheric trace gases and process tracers related to climate change and human activity. The measurement strategy delivers a process based understanding of the carbon cycle that is accurate and extensible from city to regional and continental scales. This understanding comes from contiguous maps of carbon dioxide $\left(\mathrm{CO}_{2}\right)$, methane $\left(\mathrm{CH}_{4}\right)$, carbon monoxide $(\mathrm{CO})$, and chlorophyll fluorescence (CF) collected up to 10 times per day at high spatial resolution $(\sim 4 \mathbf{k m} \times 4 \mathbf{k m})$ from geostationary orbit (GEO). These measurements will capture the spatial and temporal variability of the carbon cycle across diurnal, synoptic, seasonal and interannual time scales. The $\mathrm{CO} / \mathrm{CH} 4 / \mathrm{CO} / \mathrm{CF}$ measurement suite has been specifically selected because their combination provides the information needed to disentangle natural and anthropogenic contributions to atmospheric carbon concentrations and to minimize key uncertainties in the flow of carbon between the atmosphere and surface since they place constraints on both biogenic uptake and release as well as on combustion emissions. Additionally, GCPM's combination of high-resolution mapping and high measurement frequency provide quasicontinuous monitoring, effectively eliminating atmospheric transport uncertainties from source/sink inversion modeling. GCPM uses a single instrument, the "Geostationary Fourier Transform Spectrometer (GeoFTS)" to make measurements in the near infrared spectral region at high spectral resolution. The GeoFTS is a half meter cube size instrument designed to be a secondary "hosted" payload on a commercial GEO satellite. NASA and other government agencies have adopted the hosted payload implementation approach because it substantially reduces the overall mission cost. This paper presents a hosted payload implementation approach for measuring the major carbon-containing gases in the atmosphere from the geostationary vantage point, to affordably advance the scientific understating of carbon cycle processes and climate change.
\end{abstract}

\section{TABLE OF CONTENTS}

1. INTRODUCTION .1

2. SCIENCE FROM GEOSTATIONARY ORBIT ........3

3. THE GEOFTS INSTRUMENT CONCEPT ............8

4. THE GCPM MISSION CONCEPT ....................10

5. SUMMARY ....................................................11

ACKNOWLEDGMENTS......................................11

REFERENCES.......................................................12

BIOGRAPHIES...............................................15

978-1-4577-0557-1/12/\$26.00 C2012 IEEE

\section{INTRODUCTION}

Carbon is a fundamental component of the Earth system and the backbone of life on Earth. Its presence in the atmosphere as carbon dioxide $\left(\mathrm{CO}_{2}\right)$ and methane $\left(\mathrm{CH}_{4}\right)$ is critical to maintaining a habitable climate. Carbon exchanges (fluxes) between carbon reservoirs; atmosphere, land biosphere, ocean, and fossil fuels, form the carbon cycle as depicted in Figure 1. The atmospheric concentrations of $\mathrm{CO}_{2}$ and $\mathrm{CH}_{4}$ integrate signals from all of the processes contributing to the exchange of carbon between the atmosphere and surface. Spatial and temporal gradients in atmospheric $\mathrm{CO}_{2}$ and $\mathrm{CH}_{4}$ concentrations may be inverted to estimate the surfaceatmosphere fluxes, but to date atmospheric flux inversions have performed only for grossly under measured systems, resulting in large uncertainties and ambiguous interpretation of the resulting fluxes. Additionally, these inversions have typically been conducted for a single species, usually $\mathrm{CO}_{2}$, and lack sufficient ancillary information to disentangle signals from natural and anthropogenic processes that occur simultaneously in space and time. The problem is complicated since local signals are immediately transported by weather systems, even as they are gradually diminished by atmospheric mixing. Therefore, the challenge to

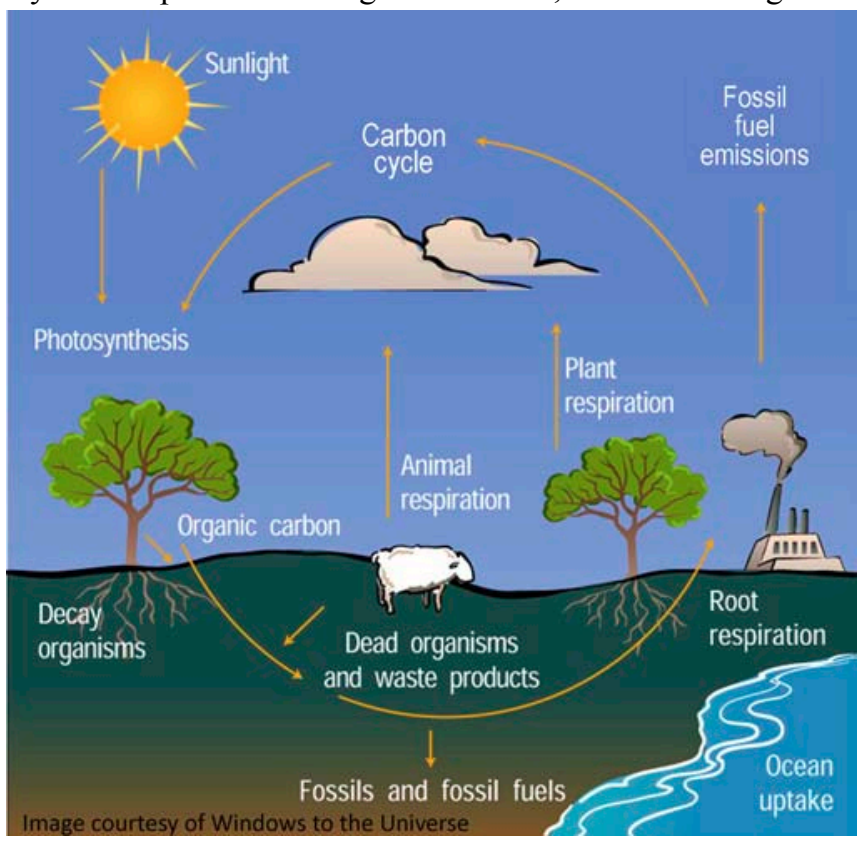

Figure 1. The carbon cycle involves continuous exchanges (fluxes) of carbon between carbon reservoirs in the atmosphere, land biosphere, ocean, and fossil fuels 
improved understanding of carbon cycle processes across space and time scales is twofold: (1) increase the spatial and temporal density of measurements so they are comparable to the spatial resolution and time step size of the models used in inversion frameworks, and (2) provide measurements of key variables that will enable models to disentangle fluxes from specific natural and anthropogenic processes (fossil fuel emissions, photosynthesis, wildfires emissions, etc.).

Carbon, in the form of coal, oil, and natural gas is the dominant element in human energy production. This massive release of long sequestered carbon into the Earth's atmosphere as $\mathrm{CO}_{2}$ from fossil fuel combustion raises concerns about the role of human activities, including land use change and land disturbance, in the Earth's carbon cycle. Given the long life-time of $\mathrm{CO}_{2}$, the impacts of human-caused changes on the global carbon cycle will be felt for hundreds to thousands of years. A process-level understanding of the carbon cycle is needed to assess and anticipate changes in $\mathrm{CO}_{2}$ and $\mathrm{CH}_{4}$ fluxes and atmospheric concentrations, and improve future projections of the carbon cycle and climate change, as increasing greenhouse gas concentrations are not only currently the primary driver of climate change but also exhibit uncertain feedback mechanisms as the planet warms.

Significant progress has been made in developing global and regional carbon budgets over the last decade, but many fundamental science questions remain. Can atmospheric concentrations of $\mathrm{CO}_{2}$ be attributed to specific natural and anthropogenic sources and sinks? Can plant uptake and respiration be disentangled from the net $\mathrm{CO}_{2}$ flux? How will the terrestrial biosphere respond to climate change (the gross flux needs to be known, not just the net flux), and can fluxes be quantified on scales that closely match the fundamental processes? Future levels of atmospheric $\mathrm{CO}_{2}$ are expected to increase due to human activities and $\mathrm{CO}_{2}$ is an essential climate variable. It is the heartbeat metric for Earth's climate. Direct observations of atmospheric $\mathrm{CO}_{2}$ is NASA priority [1] and a national need as described in the 2011 U.S. Carbon Cycle Science Plan [2], which emphasize that a better scientific understanding of the Earth's carbon cycle is both an urgent societal need as well as a challenging scientific problem. Whereas much effort over the past decade has focused on quantifying sources and sinks of $\mathrm{CO}_{2}$ and $\mathrm{CH}_{4}$ at increasingly finer spatial and temporal scales (i.e., identifying the variability in the carbon cycle), efforts at attributing this variability to underlying biogeochemical processes are still in their early stages. An achievable result for the next decade is to obtain a process-based understanding of observed carbon cycle variability that is accurate and extensible from city to regional and continental scales, and improves future projections of the carbon cycle and climate. Measurements from ground based networks, airborne platforms, and low earth orbit (LEO) satellites currently provide important information about the carbon cycle, but their data sets do not provide the full range of spatial and temporal measurements needed to understand the fine details of carbon cycle processes over large geographic regions. Simultaneous, high resolution measurements of $\mathrm{CO}_{2}, \mathrm{CH}_{4}$, carbon monoxide (CO), and chlorophyll fluorescence $(\mathrm{CF})$ in the near infrared spectral region many times a day from geostationary orbit (GEO) will provide the high resolution data set needed to understand carbon cycle processes at very fine time scales (minutes to hours to days) and small spatial scales (few $\mathrm{km}$ ) over continental size regions as illustrated in Figure 2. This new level of detailed observations over large geographic areas will reveal fresh

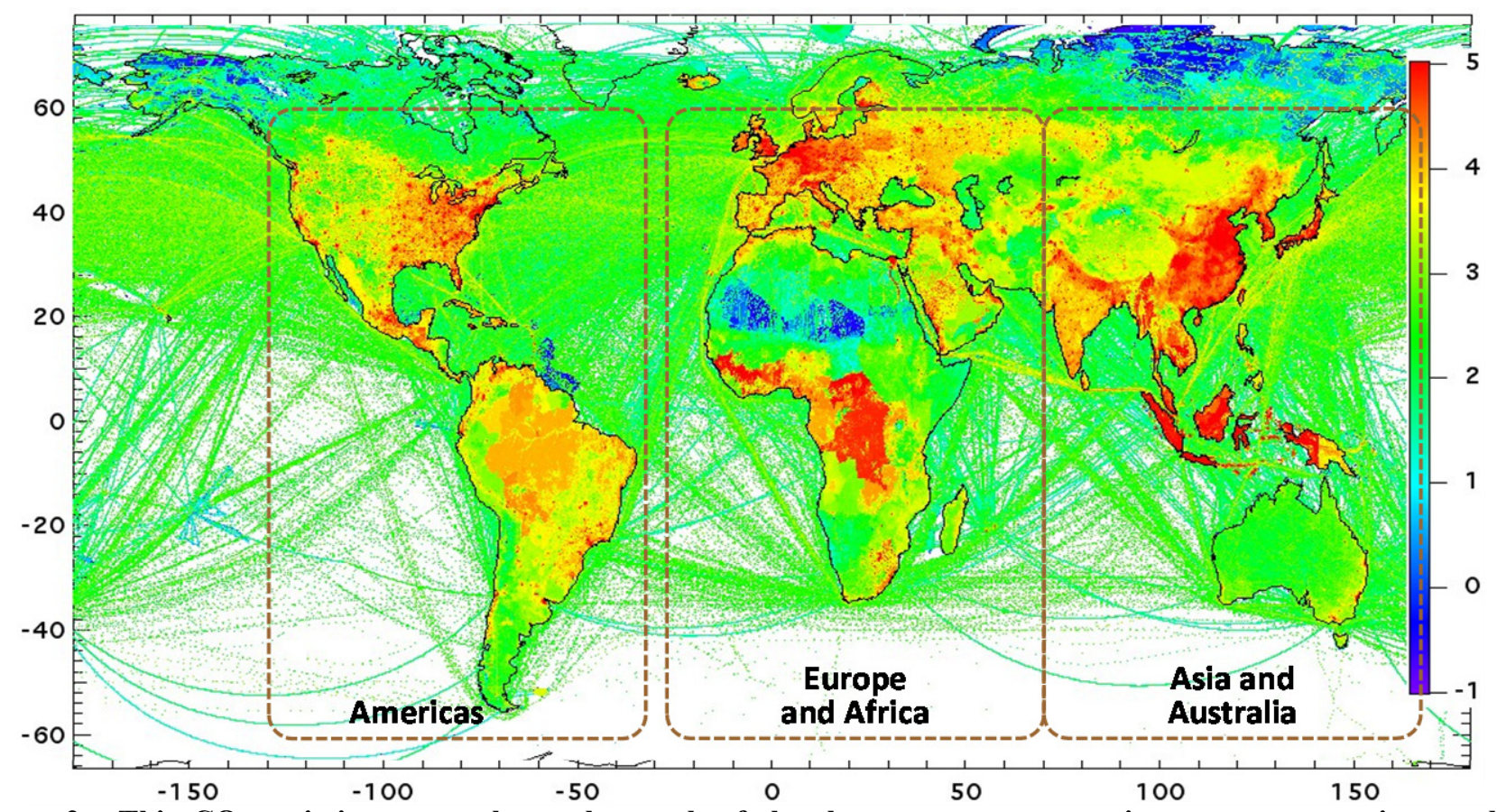

Figure 2. This $\mathrm{CO}_{2}$ emissions map shows that each of the three common geostationary vantage points enables continuous direct observations of important natural and anthropogenic emissions centers. Each vantage provides access to unique and highly uncertain aspects of the global carbon cycle. 
insights for a process-based understanding of observed carbon cycle variability that is accurate and extensible from city to regional and continental scales, and improves future projections of the carbon cycle and climate change. Because the objective is to obtain a process-based understanding of observed carbon cycle variability, which is observable all around the globe, observations are not constrained to any specific longitude. An orbit longitude near $-95^{\circ}$ would be ideal for observations of the Americas. A longitude near $20^{\circ}$ would be ideal for observations of the European and African continents while a longitude near $120^{\circ}$ would be ideal for observations of the Asian and Australian continents. Even if observations were made from a less than ideal orbit location it would have minimal impact on obtaining a process-based understanding of observed carbon cycle variability because the processes of interest occur everywhere around the globe.

Direct measurement of $\mathrm{CO}_{2}$ and $\mathrm{CH}_{4}$ provides information about their variability but not the specific causes for their variability (emissions, transport, evolution, or deposition). Measurements of just one species are rarely enough to attribute emissions to either anthropogenic or terrestrial sources. Simultaneous measurements of $\mathrm{CO}_{2}, \mathrm{CH}_{4}, \mathrm{CO}$, and $\mathrm{CF}$ are needed to disentangle anthropogenic and biogenic fluxes. Observed correlations between atmospheric concentrations of $\mathrm{CO}_{2}$ and $\mathrm{CO}$ provide critical information for improving $\mathrm{CO}_{2}$ surface flux estimates tied to the anthropogenic emissions through coupled $\mathrm{CO}_{2}-\mathrm{CO}$ inverse analyses [3]. Studies over the past decade have shown that correlations between atmospheric concentrations of $\mathrm{CH}_{4}$ and $\mathrm{CO}$ offer vital information for improving $\mathrm{CH}_{4}$ surface flux estimates tied to biomass burning through coupled $\mathrm{CH}_{4}-\mathrm{CO}$ inverse analyses [4]. Recent research indicates that accurate measurements of chlorophyll fluorescence (CF) are possible from space and provide a unique proxy for gross primary production. [5]. Eventually, this can be used to improve $\mathrm{CO}_{2}$ surface flux estimates tied to biogenic sources through coupled $\mathrm{CO}_{2}-\mathrm{CF}$ inverse analyses [6]. Simultaneous high spatial resolution measurements many times per day of $\mathrm{CO}_{2}$, $\mathrm{CH}_{4}, \mathrm{CO}$, and $\mathrm{CF}$ will provide an unprecedented "game changing" ability to track both sources and transport patterns of key greenhouse species to determine their trends and variability over numerous spatial and temporal scales, to deliver unique insights into carbon weather, and to enable anthropogenic emissions to be distinguished from biogenic sources. This ground breaking data set will greatly improve the scientific understanding of carbon cycle processes and the sources and sinks of greenhouse gases.

\section{SCIENCE FROM GEOSTATIONARY ORBIT}

Carbon cycle processes are complex. There are "point" and distributed sources of natural and anthropogenic emissions; complex transport processes, both lateral and vertical, and photochemistry driven by temperature, atmospheric composition, UV flux, and other variables. These sources, transport processes, and photochemical processes vary significantly spatially and temporally. Presently there are few observations that give direct information on short time scale carbon cycle processes (respiration, photosynthesis, atmospheric transport), and none offer an adequate direct picture of spatial and temporal patterns To understand these processes and their interactions requires measurements that have high spatial resolution over large geographic areas, frequent sampling, and a suite of correlated geophysical variables. The Geostationary Carbon Process Mapper (GCPM) is designed to do this. It will measure key atmospheric trace gases and process tracers related to climate change and human activity.

GCPM will provide a data set with unprecedented time resolved details from minutes to hours that will revolutionize the understanding of carbon cycle processes. Simultaneous high spatial resolution measurements of $\mathrm{CO}_{2}$, $\mathrm{CH}_{4}, \mathrm{CO}$, and $\mathrm{CF}$ in the near infrared spectral region many times per day from GEO will provide the data needed to understand processes which have time scales of minutes to hours. In addition, transport errors, one of the largest error sources in our understanding of carbon flux, will be greatly reduced with the spatially continuous measurements that are taken hourly, on spatial scales matched to hourly transport $(\sim 8 \mathrm{~km})$ [7]. This new level of detailed observations over large geographic areas will yield brand new insights for a process based understanding of the carbon cycle. The GEO vantage point enables continuous direct observations with high measurement density (spatial and temporal) mapping of carbon cycle processes over a third of earth's populated regions, e.g. the Americas, Europe / Africa, Asia / Australia as shown in Figure 2. Carbon cycle processes are ubiquitous around the globe. The carbon cycle processes of interest such as terrestrial and anthropogenic emissions and transport characteristics are all present but in different ratios of emphasis depending on which continental regions are observed. GCPM is not constrained to a particular orbit longitude because almost any location would provide access to observe the spatial and temporal variations in emissions over mega cities, diurnal uptake and release of greenhouse gases in cropland regions, the dynamic response of vegetation to varying illumination and stress conditions, and atmospheric transport and mixing processes. The ability to continuously stare from GEO at any region in the field of regard enables a flexible mapping capability with maximum probability of cloud avoidance which is key for determining spatial gradients, and flexibility to trade observational coverage vs. sampling frequency to capture critical events and processes.

\section{Measurements from GEO Complement Other Observations}

Measurements from ground based networks provide frequent samples but over a limited number of specific geographic locations. This leaves uncertainties regarding atmospheric concentrations in between measurement points as well as outside of the network geography. Airborne platforms provide frequent sampling over regional scale areas but only during a campaign. LEO satellites provide global observations but not frequent enough to capture fast carbon cycle processes over large geographic regions. 


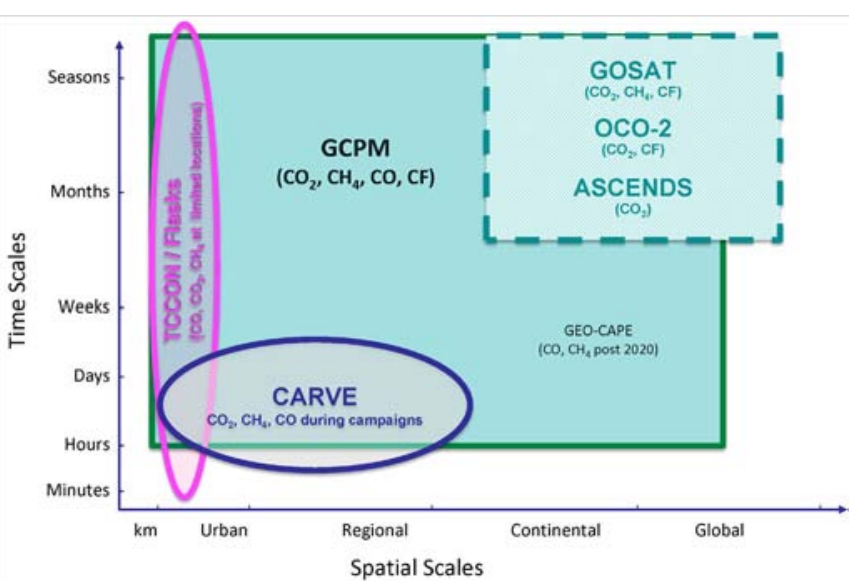

Figure 3. GCPM measurements not only cover more species but also provide vital spatial and temporal information not accessible by ground-based, airborne, and LEO satellite observations

GCPM measurements will fill the gaps in current groundbased, airborne and satellite based atmospheric composition observations as illustrated in Figure 3. NASA's carbon cycle satellite observation program of record; Orbiting Carbon Observatory 2 (OCO-2), OCO-3, and Active Sensing of $\mathrm{CO}_{2}$ Emissions over Nights, Days, and Seasons (ASCENDS), does not include $\mathrm{CH}_{4}$, the most important carbon-containing greenhouse gas after $\mathrm{CO}_{2}$. The Geostationary Coastal and Air Pollution Events (GEOCAPE) mission will be able to measure $\mathrm{CH}_{4}$, but it is not schedule to launch until after 2022.

GCPM will significantly expand NASA's satellite observation capability for mapping carbon cycle process details. GCPM measurements not only cover more species but also provide vital spatial and temporal information not accessible by ground-based, airborne, and LEO satellite observations. GCPM will make simultaneous measurements of $\mathrm{CO}_{2}, \mathrm{CH}_{4}, \mathrm{CO}$, and $\mathrm{CF}$ which is required for attribution of atmospheric $\mathrm{CO}_{2}$ and $\mathrm{CH}_{4}$ concentrations, their magnitude, distribution and variability related to human and biogenic activities. GCPM measurements many times per day will resolve the diurnal evolution of atmospheric $\mathrm{CO}_{2}$ and $\mathrm{CH}_{4}$ concentrations which is not obtainable from LEO satellite measurements. GCPM measurements will complement measurements made by LEO satellites which make polar region measurements many times a day but only provide infrequent observation revisits (two week revisit is typical - if there is no cloud cover) in mid-latitude and equatorial regions. The combination of observations from LEO and GEO will be a powerful tool for quantifying the global carbon budget and anthropogenic emissions.

\section{High Spatial and Temporal Measurements from GEO}

Population growth and economic development in the future will likely be concentrated in the developing world and lead to increased urban agglomeration at latitudes between $60^{\circ} \mathrm{N}$ and $45^{\circ} \mathrm{S}$ [8]. The largest 25 urban areas (megacities) account for $75 \%$ of the global total fossil fuel $\mathrm{CO}_{2}$ emissions. Rapid growth exceeding $10 \%$ per year is expected in developing regions. These developments will result in changes in the global patterns of fossil fuel combustion, both for primary power generation and for transportation services. Timely estimates and verification of these changes are essential for accurate bottom-up estimates used to model inferences of natural net surface fluxes from top-down measurements of $\mathrm{CO}_{2}$. Furthermore, direct verification of trends in regional fossil fuel combustion will aid evaluation of the socio-economic conditions prevalent at the outset of various future scenarios of $\mathrm{CO}_{2}$ emissions and the atmospheric accumulation used to force climate model projections.

Measurements from GEO several times per day with $a<8$ $\mathrm{km}$ ground sampling distance over populated continents will observe multiple large urban areas and provide never before seen details of anthropogenic emissions. Figure 4 shows a simulated $\mathrm{CO}_{2}$ map of France and how high spatial resolution measurements would make the urban dome over Paris and a large power plant plume in Lyon clearly identifiable [9]. GCPM will measure the spatial and temporal evolution of atmospheric $\mathrm{CO}_{2}$ and resolve its diurnal variability on city to continental scales.

\section{High Resolution $\mathrm{CO}_{2}$ Measurements from $\mathrm{GEO}$}

$\mathrm{CO}_{2}$ is the most important anthropogenic greenhouse gas. GEO measurements many times per day will provide crucial information about how the fluxes of $\mathrm{CO}_{2}$ from terrestrial ecosystems and urban centers vary on diurnal, synoptic, seasonal and interannual time scales. Scientific understanding of the carbon cycle has matured but fundamental questions remain concerning whether continental regions are net carbon sources or sinks.

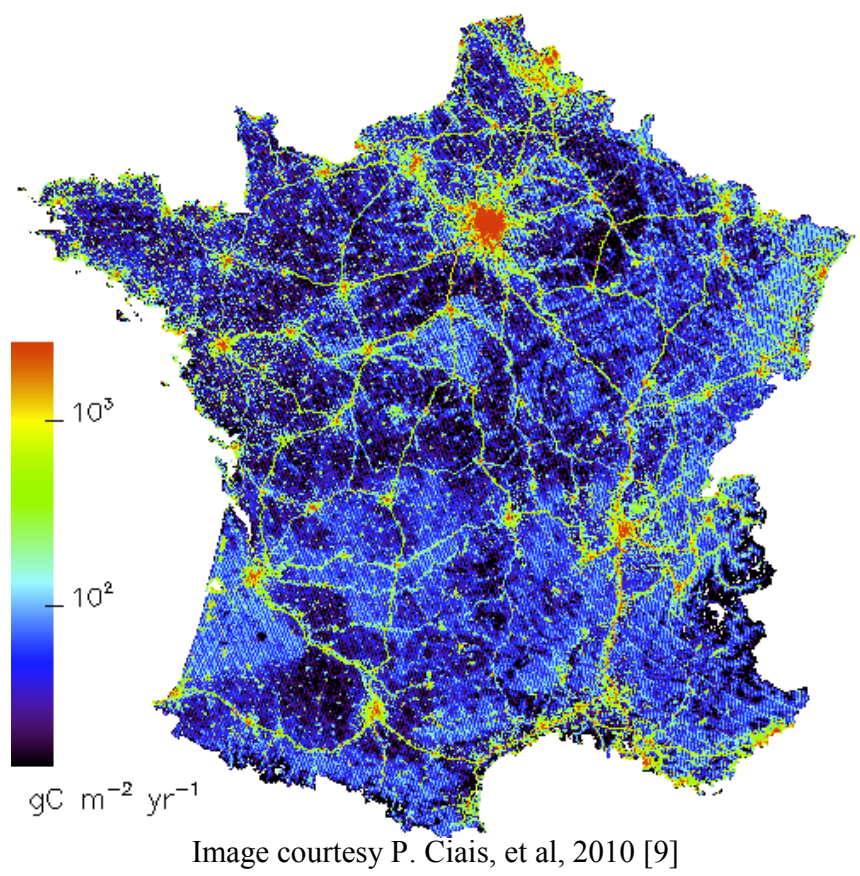

Figure 4. GCPM will measure the spatial and temporal evolution of atmospheric $\mathrm{CO}_{2}$ and resolve its diurnal variability on city to continental scales 


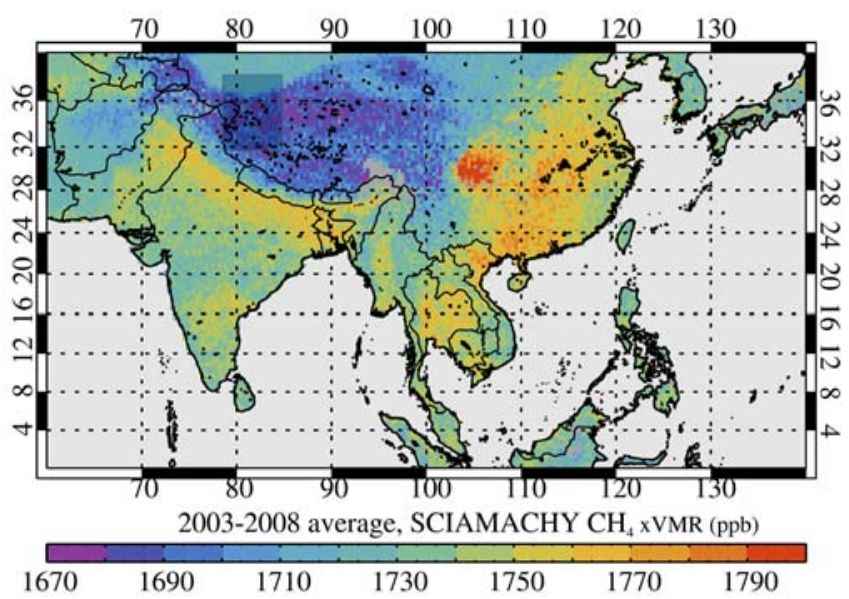

Figure 5. GCPM will measure the spatial and temporal evolution of atmospheric $\mathrm{CH}_{4}$ and resolve its diurnal variability on city to continental scales

Annually, plants absorb roughly as much $\mathrm{CO}_{2}$ through photosynthesis as they emit through respiration. Consequently the net ecosystem exchange (NEE) of $\mathrm{CO}_{2}$ between the land and atmosphere varies around zero. The uncertainties in gross primary production (GPP; $\mathrm{CO}_{2}$ taken up in photosynthesis) and ecosystem respiration (Re; $\mathrm{CO}_{2}$ released back to the atmosphere from plant metabolism and dead plant material decay or combustion) must be wellconstrained to know even the sign of NEE. Both GPP and Re contain uncertainties $[10,11]$ that compound further when combined into NEE. Many measurements per day are required to understand and predict the diurnal pattern of NEE, as daily variations in soil moisture, diurnal freezethaw cycling, and morning to afternoon weather cycling patterns alter projected diurnal NEE based on solar radiation alone [12]. High spatial resolution measurements of atmospheric $\mathrm{CO}_{2}$ many times a day will enable the reduction of flux uncertainties on scales appropriate to resolve regional variations.

\section{High Resolution $\mathrm{CH}_{4}$ Measurements from $\mathrm{GEO}$}

Atmospheric $\mathrm{CH}_{4}$ is the second most important anthropogenic greenhouse gas, exhibiting both a direct and an indirect radiative forcing [13]. $\mathrm{CH}_{4}$ is an extremely effective absorber of radiation, though its atmospheric abundance is less than $\mathrm{CO}_{2}$ and its lifetime in the atmosphere is brief (10-12 years), compared to some other greenhouse gases (such as $\mathrm{CO}_{2}, \mathrm{~N}_{2} \mathrm{O}, \mathrm{CFCs}$ ). $\mathrm{CH}_{4}$ has both biogenic and anthropogenic sources. It is released as part of the biological processes in low oxygen environments, such as in swamplands or in rice production (at the roots of the plants). Over the last century, human activities such as growing rice, raising cattle, natural gas production and mining coal have added to the atmospheric abundance of $\mathrm{CH}_{4}$. The abundance of atmospheric $\mathrm{CH}_{4}$ has nearly tripled since the industrial revolution, but the contribution from individual sources remains unclear. Simultaneous high resolution measurements of atmospheric $\mathrm{CO}_{2}, \mathrm{CH}_{4}, \mathrm{CO}$ and CF many times a day will make it possible to distinguish anthropogenic and biogenic sources of $\mathrm{CO}_{2}$ and $\mathrm{CH}_{4}$. Long term observations will reveal how secular trends in $\mathrm{CO}_{2}$ and $\mathrm{CH}_{4}$ correlate with key physical, biological and socioeconomic markers such as surface temperature, wetlands, vegetation type and distribution, land-use changes and industrial activity. Figure 5 shows a $\mathrm{CH}_{4}$ map derived from SCIAMACHY satellite data of southern and eastern Asia which, on average, has the highest methane column averages on Earth. While emissions from rice paddies, agriculture, and industrial processes are suspected to be very high in this region, wetlands, and high ruminant density also contribute to the high $\mathrm{CH}_{4}$ abundance [14].

\section{High Resolution $\mathrm{CF}$ and $\mathrm{O}_{2}$ Measurements from GEO}

Remote sensing of terrestrial vegetation is a vital tool for trend monitoring and carbon flux estimation. Traditional methods using satellite data are mainly based on indices such as the Normalized Difference Vegetation Index (NDVI), which is derived from hyper-spectral reflectance measurements in the visible to near-infrared spectral region. CF offers a more direct insight into photosynthesis. During photosynthesis, chlorophyll is in its excited state after absorption of visible solar energy. The excited state can either be quenched by carbon fixation, heat dissipation or reemission via fluorescence at longer wavelengths $[15,16$ and references therein]. The retrieval of solar-induced CF from space was proposed as the scientific Fluorescence Explorer (FLEX) satellite mission [17], submitted to the European Space Agency (ESA) Earth Explorer program.

Measurements of CF near the oxygen A absorption band provides a direct measure of photosynthetic activity or GPP because $\mathrm{CF}$ is a first order by-product of photosynthesis [16, $18,19,20]$. Recent studies have shown that CF can be accurately retrieved using high resolution spectra in the 750 $\mathrm{nm}$ region, covering part of the fluorescence emission spectrum $[5,6,21]$. The retrieval is based on the filling in of

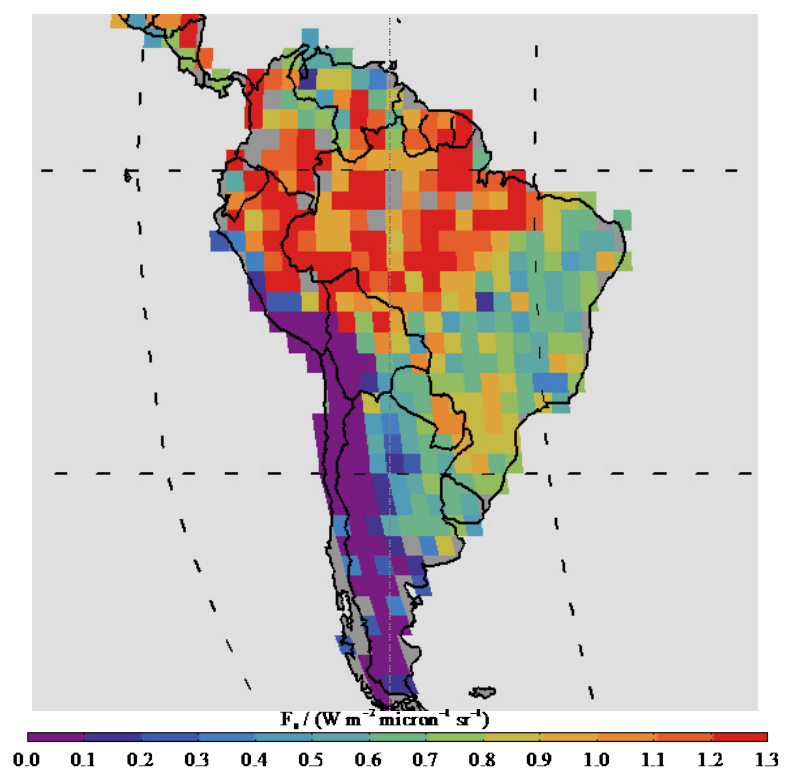

Figure 6. GCPM will measure the spatial and temporal evolution of chlorophyll fluorescence at much finer scales than current LEO satellite observations 
Fraunhofer lines. This has been proven using real data from the GOSAT satellite $[5,21]$. Large-scale patterns of fluorescence were found to exhibit a strong linear relationship with current best estimates of GPP [5]. Figure 6 shows the limited resolution of CF information available from current LEO satellite data. Observations from the GEO vantage point would allow retrievals of CF over the entire diurnal cycle, providing greater insight into the dynamic response of the vegetation to varying illumination and stress conditions (e.g. mid-day stomatal closures under mild drought stress). In addition, measurements of the same scene under varying irradiance (i.e. local time) would help disentangle photosynthesis rates from changes in photosynthesis and fluorescence yield as a function of light saturation. It has been shown that global estimates of GPP based on fluorescence compare well with other global products of GPP [5, 6, 21]. Frequent measurements during local sunlit times will produce unique global carbon cycle observations, which provide additional constraints for decoupling gross and net terrestrial carbon flux estimates. CF-based estimates of GPP can be used to constrain bottomup model flux estimates of the terrestrial biosphere. These ecosystem models, which form the land surface component of larger coupled climate models, simulate GPP as part of the full cycling of carbon and water processes in ecosystems [22]. By constraining simulated GPP with observed GPP, the inter-model variability of NEE calculated downstream is



Figure 7. The GCPM uses just three spectral regions to measure all species. reduced. This inter-model variability drives the uncertainty in the global terrestrial carbon cycle [23]. GCPM data will improve two types of flux models: bottom-up land surface models, constrained by fluorescence-based GPP; and atmospheric inversion models, constrained by atmospheric measurements of dry air mole fraction, $\mathrm{X}_{\mathrm{CO} 2}$.

Just as CF measurements help improve estimates of the terrestrial carbon flux, measurements of $\mathrm{CO}$, a strong tracer of fossil fuel combustion, can be used to help attribute $\mathrm{CO}_{2}$ emissions to anthropogenic sources. Observed correlations between atmospheric concentrations of $\mathrm{CO}_{2}$ and $\mathrm{CO}$ offer critical information for improving $\mathrm{CO}_{2}$ surface flux estimates through coupled $\mathrm{CO}_{2}-\mathrm{CO}$ inverse analyses [3]. Analysis has shown that column $\mathrm{CO}$ measurements improve net $\mathrm{CO}_{2}$ flux estimates when assimilated into a global chemical transport model [24, 25]. Transport characteristics can be derived from dynamical tracers such as $\mathrm{CO}$, which can also be used to separate combustion sources of $\mathrm{CO}_{2}$ from terrestrial sources and sinks. With the small spatial scale of GCPM measurements, this correlation is expected to be even stronger than shown in previous global scale analysis In addition, $\mathrm{CO}$ can be used to differentiate methane sources such as wetlands (low CO emissions) and biomass burning (high $\mathrm{CO}$ emissions).

Measurements in the oxygen A absorption band, near 760 $\mathrm{nm}$, are of great importance for scaling total column retrievals of $\mathrm{CO}_{2}, \mathrm{CH}_{4}, \mathrm{CO}$, and $\mathrm{H}_{2} \mathrm{O}$ in order to obtain volume mixing ratios [26] and for light path corrections [27, $28,29]$. The retrieved surface pressure can be validated from meteorological models. Surface pressure retrievals from cloud-free $\mathrm{O}_{2}$ A-band measurements and their validation provide important insight into the quality of the instrument calibration [30]. They can also provide insight into retrievals that are affected by similar radiation transport processes, such as the retrievals of total columns of $\mathrm{CO}_{2}$, $\mathrm{CH}_{4}, \mathrm{CO}$, and $\mathrm{H}_{2} \mathrm{O}$.

\section{GEO Observation Measurement Requirements}

GCPM uses imaging spectroscopy for atmospheric composition remote sensing. Imaging spectroscopy is the acquisition of images that have a spectrum of the energy arriving at the sensor in each spatial resolution element. These spectra are used to derive information on the composition of trace gases and aerosols as well as the physical state of the atmosphere based on the absorption and scattering of solar radiation. Figure 7 shows the upwelling radiance at the top of the atmosphere and the molecular absorption windows for the species of interest. The general shape of the spectrum is dominated by the solar spectral irradiance and the absorption features of the atmosphere.

A spectral resolution of $0.3 \mathrm{~cm}^{-1}$ is required to fully sample the line shapes of $\mathrm{CO}_{2}, \mathrm{CH}_{4}$, and $\mathrm{CO}$ and separate them from interferents [31]. A spectral resolution of $2 \mathrm{~cm}^{-1}$ is needed for $\mathrm{CF}$ to see a small change in the Fraunhofer lines on top of other signals (aerosols, water vapor, etc.). 
Frankenberg et al [5] illustrates the signal that is pulled out, and quantified the error, as a function of resolution and noise. His analysis indicates that the range of SNR-200 and spectral resolution $0.01 \mathrm{~nm}$ to SNR of 1000 and a spectral resolution of $0.1 \mathrm{~nm}$ will result in about $20 \%$ error on fluorescence (or $0.5 \%$ of continuum level, where the fluorescence signal is up to $2.5 \%$ ). A spectral resolution of $0.6 \mathrm{~cm}^{-1}$ for $\mathrm{O}_{2}$ is sufficient to retrieve surface pressure with sufficient accurately. This was shown by analysis done for the OCO-2 instrument [31].

The $\mathrm{CO}_{2}$ column measurement precision requirement is tied to the magnitude of diurnal cycles as well as the hemispheric gradients. Typically, the $\mathrm{CO}_{2}$ change from northern to southern latitudes ( +60 to -60 degrees) is about 6 ppm, with an annual cycle of $\sim 6 \mathrm{ppm}$, and a secular increase of about $2 \mathrm{ppm}$. A precision of $1 \mathrm{ppm}$ is required to be able to infer fluxes from this small variability. Like $\mathrm{CO}_{2}$, methane has relatively small variability, and its latitudinal gradient from the north pole to the south pole is about $1 \%$, so it needs to be measured with enough precision to see high concentrations and longitudinal gradients. $\mathrm{CO}$ has a lifetime of a few months and consequently a much wider dynamic range in the atmosphere, so measuring the concentration to $10 \%$ is adequate to see gradients and anthropogenic sources, making it an ideal transport tracer.

Current CF retrievals from GOSAT are limited by high single-measurement noise as well as a low number of total observations, requiring substantial averaging in time and space. GCPM would both reduce single-measurement noise through an enlarged spectral window dedicated for $\mathrm{CF}$ as well as far more frequent measurements.

The primary use of the $\mathrm{O}_{2} \mathrm{~A}$-band is the concurrent retrieval of aerosol properties, the main driver for retrieval uncertainties. The retrieval follows the multi-band technique developed for OCO-2, where the A-band is indispensable.

Column abundance is the appropriate measurement for the target species, as $\mathrm{CO}_{2}$ is well-mixed, and the sensitivity of the near infrared measurements is fairly uniformly distributed through the atmosphere for $\mathrm{CO}_{2}, \mathrm{CH}_{4}$ and $\mathrm{CO}$.

From GEO the full extent of the earth is +/- 8.6 degrees off nadir which defines the field of regard needed to make observations anywhere over the earth disk. As shown in Figure 1, there are significant latitudinal gradients in $\mathrm{CO}_{2}$ fluxes, and all landmasses, or longitudes, have this feature. So regardless of which landmasses GCPM samples, the measurements will capture critical carbon processes; tropical wetlands and forests, agricultural areas, urbanized regions and large cities, etc.. Therefore, GCPM is relatively insensitive to orbit longitude. There will be some latitudinal dependence of the sensitivity of the measurements primarily due to solar geometry and surface properties. The tropical regions will have favorable geometry during all seasons, and mid-latitudes will have better sensitivity during local summer and the surrounding months.
The main driver for ground sampling distance is the desire to see through holes in between clouds, and to sample at scales that match the processes being studied. Analysis of MODIS data shows that a $<7 \mathrm{~km}$ footprint will yield about $15 \%$ cloud free data [32] over a continental size area of interest in an hour. Typically, an airmass will be transported $\sim 8 \mathrm{~km}$ in one hour, so sampling with footprints of $<8 \mathrm{~km}$ hourly will allow GCPM to track airmass travel and evolution. This data will significantly reduce the impact of transport errors on flux estimates [33].

Fast carbon cycle processes change significantly over the course of the day; fluorescence changes with sunlight, and anthropogenic emissions have daily cycles. These cycles typically go from their minimum to their maximum in 4 to 8 hours. Hourly sampling will capture their time dependence, even if some samples are lost to cloud contamination. Sampling over a two year period will capture variability on seasonal and interannual time scales. The measurement requirements for the GCPM are summarized in Table 1.

Table 1. The GCPM measurement requirements

\begin{tabular}{|c|c|c|c|c|c|}
\hline Species & $\mathrm{CO}_{2}$ & $\mathrm{CH}_{4}$ & $\mathrm{CO}$ & $\mathbf{C F}$ & $\mathbf{O}_{2}$ \\
\hline $\begin{array}{c}\text { Spectral } \\
\text { Window }(\mathrm{s}) \\
\left(\mathrm{cm}^{-1}\right)\end{array}$ & $\begin{array}{l}6190- \\
6380\end{array}$ & $\begin{array}{l}4210-4260 \\
5950-6100\end{array}$ & $\begin{array}{l}4210- \\
4260\end{array}$ & $\begin{array}{l}13175- \\
13225\end{array}$ & $\begin{array}{l}13000- \\
13170\end{array}$ \\
\hline $\begin{array}{c}\text { Spectral } \\
\text { Resolution } \\
\left(\mathrm{cm}^{-1}\right)\end{array}$ & 0.3 & 0.3 & 0.3 & $\begin{array}{c}2 \\
(0.1 \mathrm{~nm})\end{array}$ & 0.6 \\
\hline $\begin{array}{c}\text { Precision } \\
(1 \sigma)^{*}\end{array}$ & $0.33 \%$ & $1 \%$ & $10 \%$ & $5 \%$ & $0.33 \%$ \\
\hline $\begin{array}{c}\text { Vertical } \\
\text { Resolution }\end{array}$ & \multicolumn{5}{|c|}{ Column abundance } \\
\hline $\begin{array}{l}\text { Field of } \\
\text { Regard }\end{array}$ & \multicolumn{5}{|c|}{$+/-8.6$ degrees from nadir } \\
\hline $\begin{array}{c}\text { Ground } \\
\text { Sampling } \\
\text { Distance }\end{array}$ & \multicolumn{5}{|c|}{$<8 \mathrm{~km}$ at nadir } \\
\hline $\begin{array}{c}\text { Sampling } \\
\text { Interval }\end{array}$ & \multicolumn{5}{|c|}{$\sim$ hourly } \\
\hline $\begin{array}{l}\text { Sampling } \\
\text { Period }\end{array}$ & \multicolumn{5}{|c|}{$\sim 12$ daylight hours per day for $\sim 2$ years } \\
\hline
\end{tabular}

\section{GEO Measurements Summary}

The GCPM provides fundamental advances in space-based remote sensing of carbon cycle processes.

$\checkmark$ Complete, contiguous continental scale mapping with a high spatial resolution ( $4 \mathrm{~km} \times 4 \mathrm{~km}$ at nadir)

$\checkmark$ Hourly/daily revisit frequency for detection of fine details in diurnal photosynthetic cycle (potentially unlocking respiration signal), measuring evolution of urban domes, and accurately resolving atmospheric transport

$\checkmark$ Simultaneous measurement of the $\mathrm{CO}_{2} / \mathrm{CH}_{4} / \mathrm{CO} / \mathrm{CF}$ geophysical suite enables disentanglement of natural and anthropogenic contributions to the atmospheric carbon concentrations and minimize uncertainties in the flow of carbon between the atmosphere and surface since they place constraints on both biogenic uptake and release as well as combustion emissions 


\section{The GeofTS InSTRUMent CONCEPT}

GCPM uses a single instrument, the "Geostationary Fourier Transform Spectrometer (GeoFTS)" [34]. It is an imaging spectrometer based on a Michelson interferometer design. As a class of instruments, Fourier Transform Spectrometers (FTS) have a well demonstrated record of providing Earth observations that address a broad range of science objectives. Instrument designs similar to the GeoFTS design have successfully flown in space on a number of missions including the Atmospheric Trace Molecule Spectroscopy (ATMOS) experiment [35], the Tropospheric Emission Spectrometer (TES) [36], the Cross-Track Infrared Sounder (CrIS) [37], and the Greenhouse Gases Observing Satellite (GOSAT) [38]. In addition, a FTS-based instrument offers many important advantages compared to alternative instrument designs such as Fabry-Perot, gas correlation, or dispersive spectrometers. FTS advantages include broad spectral coverage at high resolution, inherent wavelength calibration, 2-D imaging capability, small size to achieve high spectral resolution, and immunity to scattered and stray light [39].

Figure 8 shows the $60 \mathrm{~kg}$, half meter cube size configuration of the GeoFTS instrument. It uses all high TRL components and the instrument design is modular with many identical assemblies to reduce complexity and development cost. The GeoFTS captures radiation entering the instrument via a two axis gimbaled line-of-sight pointing mirror. The line-ofsight pointing mirror brings light from the entrance aperture into the fore optics module which compresses the optical beam before directing it into the interferometer module. The Michelson interferometer has a fixed optical length arm and a variable optical length arm. The spectral resolution of the interferometer is controlled by the optical path difference mechanism. The mechanism is a friction-free flexure based design which does not require lubricants and has no inherent wear-out risks. The full size life test unit mechanism shown in Figure 9 is currently in test and has so far completed the equivalent of four years of operation in space, which is twice the design life of the GCPM mission. With over two million full stroke cycles under flight like conditions (hard vacuum at minus 100 degrees centigrade), no discernable changes in mechanism behavior have occurred. With a cube corner mirror the mechanism can provide up to $10 \mathrm{~cm}$ of optical path difference although GCPM measurements only require about $3 \mathrm{~cm}$ of optical path difference to achieve the required $0.3 \mathrm{~cm}^{-1}$ spectral resolution. Modulated light leaving the interferometer passes through a series of dichroic beam splitters separating the light into the three spectral regions of interest for measuring GeoFTS target species as depicted in Figure 7. The light exiting the dichroic beam splitters enters into three identical camera optics modules and focal plane array thermal-mechanical modules. The dichroic beam splitters are readily available commercial units and the FPA thermal- mechanical modules are build-to-print copies of the units made for the NASA OCO-2 instrument. A space flight proven miniature cryocooler [40] maintains the operating temperature of the FPAs to around $220 \mathrm{~K}$ which makes the detector dark current noise level negligible. Each FPA is designed for a specific spectral region, but their read out integrated circuits (ROICs) are identical based on a JPL developed high performance in-pixel digitization Read Out Integrated Circuit [41]. The ROIC has a 128x128, $60 \mu \mathrm{m}$ pixel format

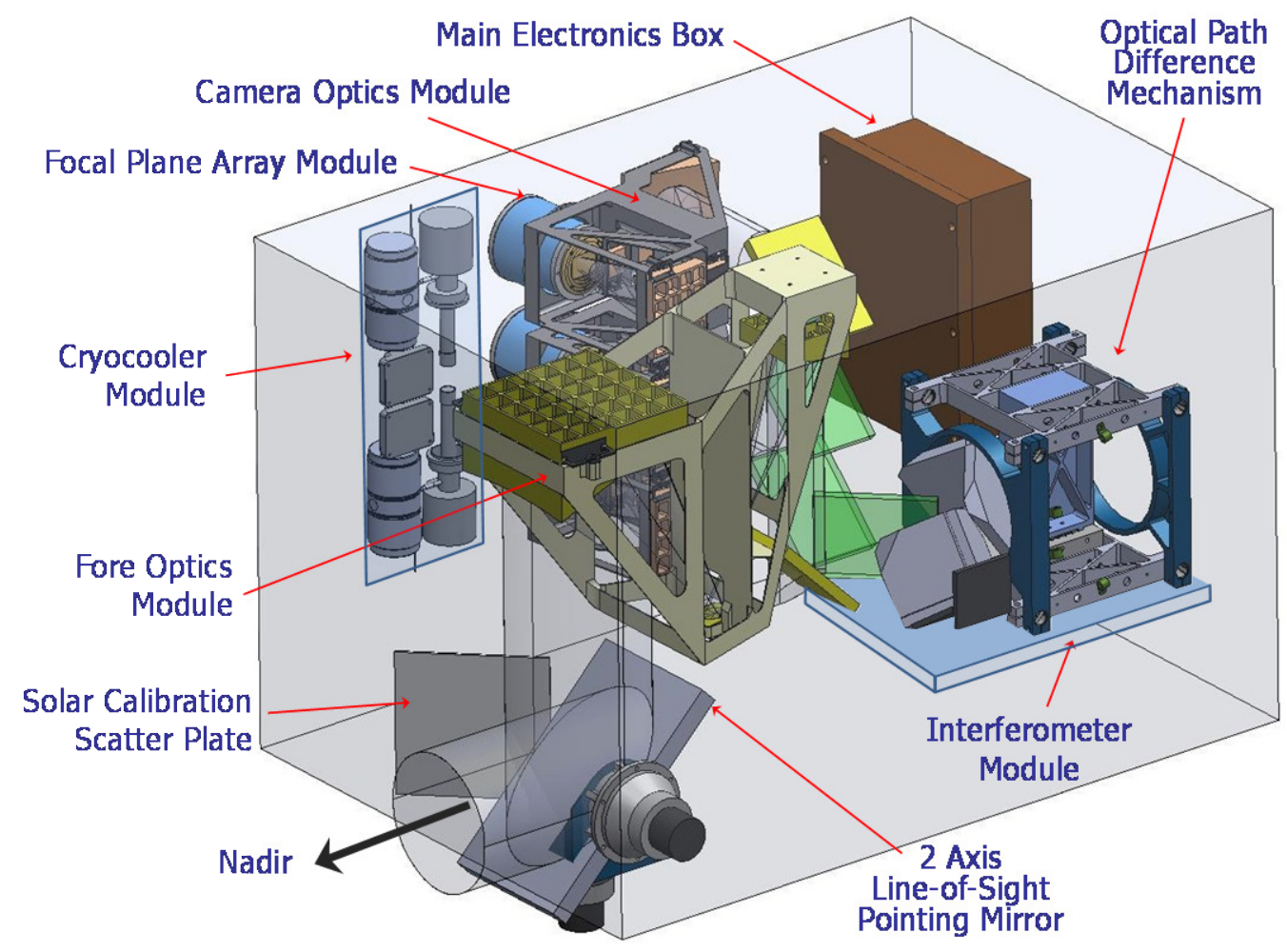

Figure 8. The GeoFTS opto-mechanical design is modular and uses high TRL components and assemblies 


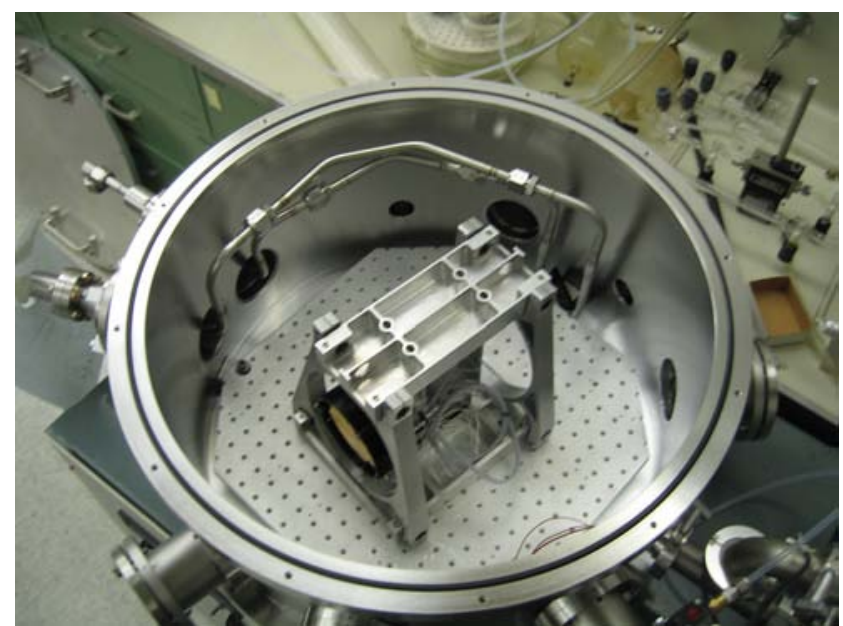

Figure 9. The GeoFTS optical path difference mechanism completed over two million full stroke cycles under flight like thermal vacuum conditions

with a separate, individual charge amplifier, analog-todigital converter (ADC) and reset circuitry in each of the 16,384 pixels, and provides 14 bit resolution. Digital output eliminates the need for off-chip analog signal processing electronics. All pixels can be read out at the same time (snapshot mode) at rates up to 16,000 times per second although GCPM measurement requirements can be met with readout rate of around $5 \mathrm{kHz}$. The snapshot mode readout eliminates problems with conventional "rolling readouts" where pixels are readout sequentially which introduces artifacts from crosstalk between pixels when adjacent pixels reset. The JPL ROIC is made in CMOS which is compatible with nearly all common photo-sensitive detector arrays such as SiPIN, for UV-Vis-NIR FPAs as well as InSb, InGaAs, or $\mathrm{HgCdTe}$ for SWIR-MWIR FPAs. ROICs like the one under test shown in Figure 10 will be hybridized with silicon p-type, intrinsic, n-type (SiPIN) diode detector arrays from Raytheon Vision Systems for the NASA Earth Science Technology Office funded GEO-CAPE Read Out Integrated Circuit (ROIC) In-Flight Performance Experiment (GRIFEX) mission which will validate the in space performance of the ROIC/FPA. An additional benefit of the GRIFEX design that will be validated in space is the FPA interface to the all-digital signal chain electronics that GeoFTS will use.

To minimize cost and complexity, the GeoFTS will use a copy of the GRIFEX Vis-NIR FPA and all-digital signal chain electronics for the $0.7 \mu \mathrm{m}$ channel. For the other two FPAs the JPL ROIC will be hybridized with thinned HgCdTe. Three FPAs with identical ROICs and signal chain electronics each with an appropriate photosensitive diode array for the spectral regions shown in Figure 7 will cover the GeoFTS spectral range from $2.5 \mathrm{um}$ to $0.7 \mathrm{um}$ and achieve the needed high frame rates at 14 bit resolution. Each completely digital FPA sends its digital data stream to a dedicated on-board data processing unit that converts the digitized interferogram into spectra. An FPGA based data collector unit combines the data from each of the data processing units and applies lossless compression to reduce the data volume and packetize the data for downlinking. It and all other instrument operations are managed by an off the shelf BAE Rad750 singleboard computer. The overall instrument design is modular with several identical assemblies such as the camera optics modules, the focal plane array thermal-mechanical modules, and the FPA ROICS and data processing units which all have space flight heritage.

As an imaging spectrometer, the GeoFTS instrument acquires a spectrally-resolved image of its instantaneous field-of-view scene by holding the line-of-sight fixed on the scene for the period of time needed to record interferograms of the scene. A square pixel array maps the scene with spatial sampling defined by the optical system design. The GeoFTS has a $512 \mathrm{~km}$ x $512 \mathrm{~km}$ instantaneous field-of-view which is imaged onto a $128 \times 128$ pixel FPA to provide a $4 \times 4$ $\mathrm{km}$ size pixel footprint at nadir. An interferogram is recorded in every pixel while the scene is observed. The interferograms are Fourier transformed into spectra by the FPA signal chain electronics to reveal absorption features at different wavelengths of the species of interest. Hourly sampling will capture the spatial and temporal variations of the GCPM species of interest.

From GEO the angular extent of Earth is about $\pm 8.6^{\circ}$ from nadir. The GeoFTS instrument has its own line-of-sight pointing system that uses a two degree-of-freedom pointing mirror to steer the instrument line-of-sight to any location over the full earth disk in any sequence/pattern desired providing total flexibility in the choice of observing patterns. One simple pattern could map the continental U.S. as depicted in Figure 11. A continental U.S. observation campaign would consist of 32 scenes observed one at a time in a boustrophedonic ("as the ox plows") sequence. If each scene is observed for 30 seconds, coverage of the entire continental U.S. would be accomplished in about 16 minutes. Random non gridded patterns are also possible.

The GCPM type of spatial and temporal mapping has been demonstrated by the $\mathrm{CO}_{2}$ measurements currently being acquired with the California Laboratory for Atmospheric

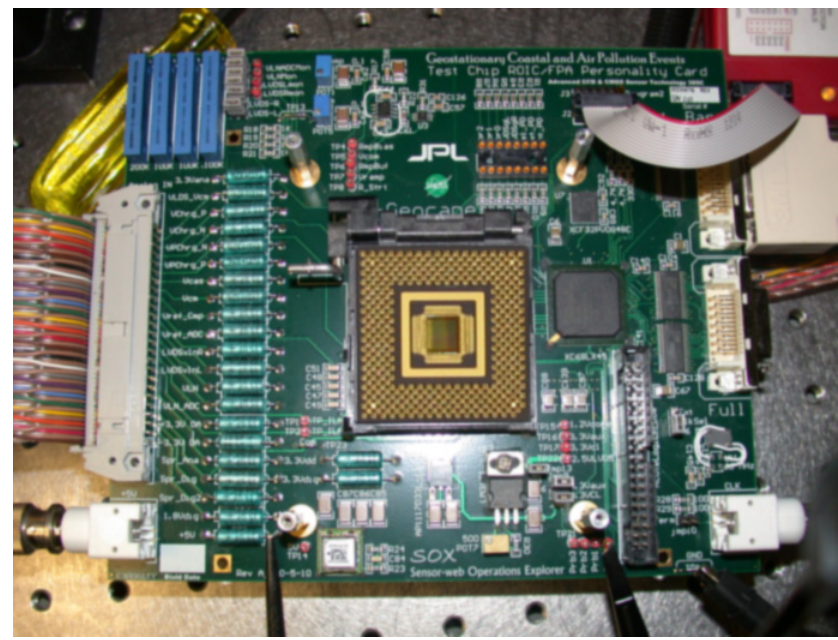

Figure 10. The JPL In-Pixel ROIC/FPA test set up 


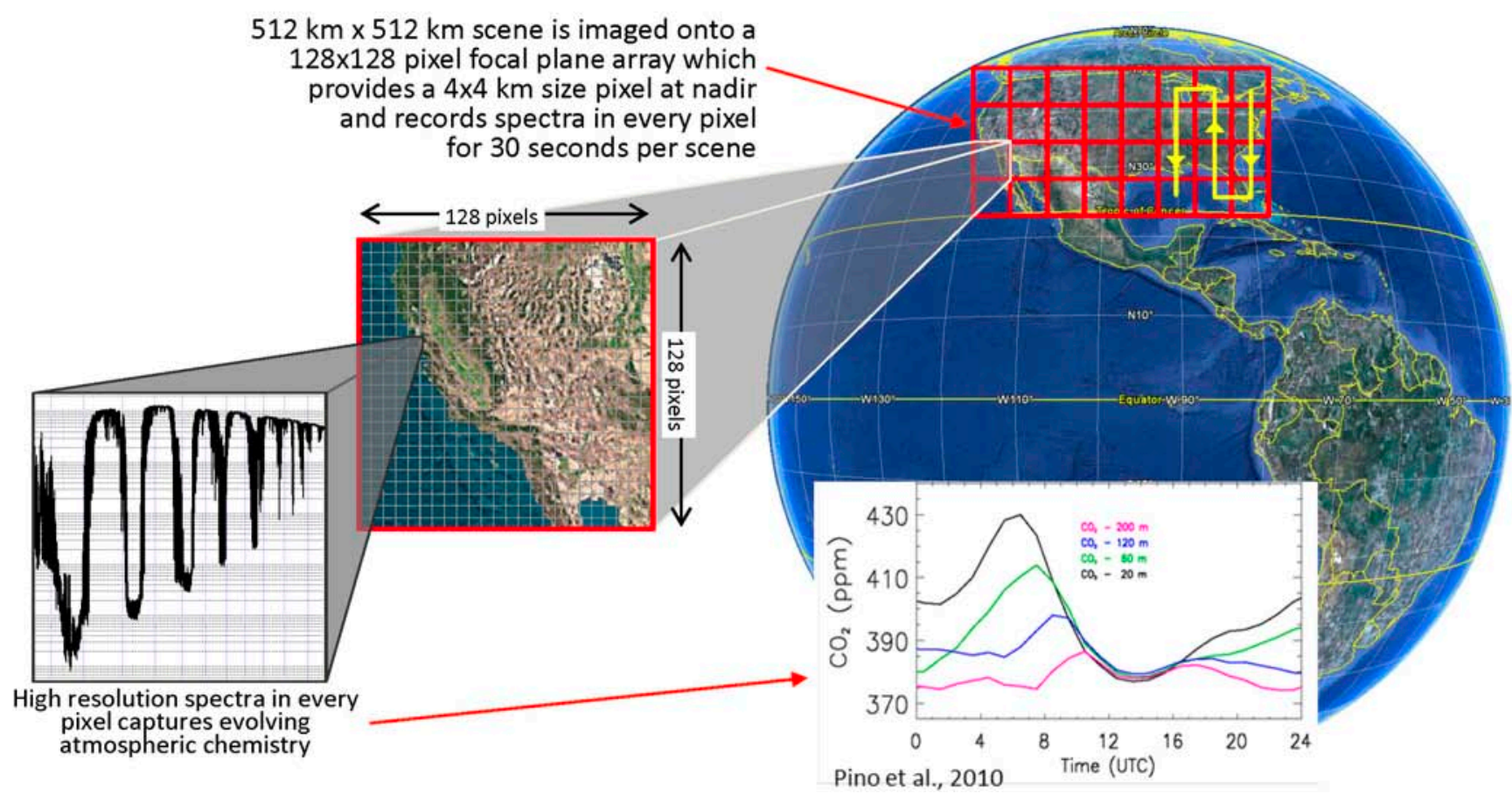

Figure 11. GeoFTS observations can be made over the full earth disk in any sequence or pattern desired

Remote Sensing (CLARS) spectrometer. The CLARS observatory shown in Figure 12 overlooks the Los Angeles basin from a geostationary altitude of $1.7 \mathrm{~km}$. The CLARS Fourier Transform IR spectrometer makes high resolution $\mathrm{CO}_{2}$ measurements over the Los Angeles basin several times per day to capture the spatial and temporal variations of $\mathrm{CO}_{2}$ during each day. GCPM maps would be similar but on a much larger spatial / continental scale.

\section{THE GCPM MISSION CONCEPT}

In the past, NASA GEO missions like the Tracking and Data Relay Satellite System (TDRSS) have been implemented as a dedicated mission that involved NASA buying a GEO compatible spacecraft, large launch vehicle, and development of a dedicated ground operations center. This dedicated mission approach is expensive and is why there are so few NASA and NOAA GEO missions. NASA has studied a lower cost alternative "hosted payload" mission implementation approach for several years [42, 43]. The GEO hosted payload approach has a government payload "hosted" as a secondary payload on a commercial GEO communications satellite mission [44, 45]. Hosted payloads can allow the government an opportunity to leverage an already planned or existing satellite bus, launch vehicle, and satellite operations, which permits government space missions to be planned and implemented on shorter cycles. Placing a hosted payload on a commercial satellite costs a fraction of the amount of building, launching, and operating an entire satellite. The commercial partner only charges for the integration of the payload with the spacecraft and the marginal use of resources such as power, launch services, and operations. The total cost to the hosted payload provider is far below that of deploying an independent, government-owned satellite for the payload [46, 47].
GEO satellite builders and commercial communications systems operators have formed a trade association to advance the use of hosted payloads on commercial satellites [48]. They are developing processes and interfaces to offer timely, cost-effective options to accommodate secondary, hosted payloads $[49,50]$. A hosted payload on a commercial communications satellite mission has the opportunity to use established commercial infrastructure and to purchase telemetry services from the satellite operator. Continuous downlink from geostationary orbit is possible because the satellite remains in the same fixed location over the ground station for the life of the mission. The concept of operations shown in Figure 13 permits continuous direct data transfer from the GeoFTS instrument to host transponders to ground receiving stations (a bent pipe downlink strategy). Data is transmitted from the satellite operator's ground operations center to the GeoFTS operations center where it is processed

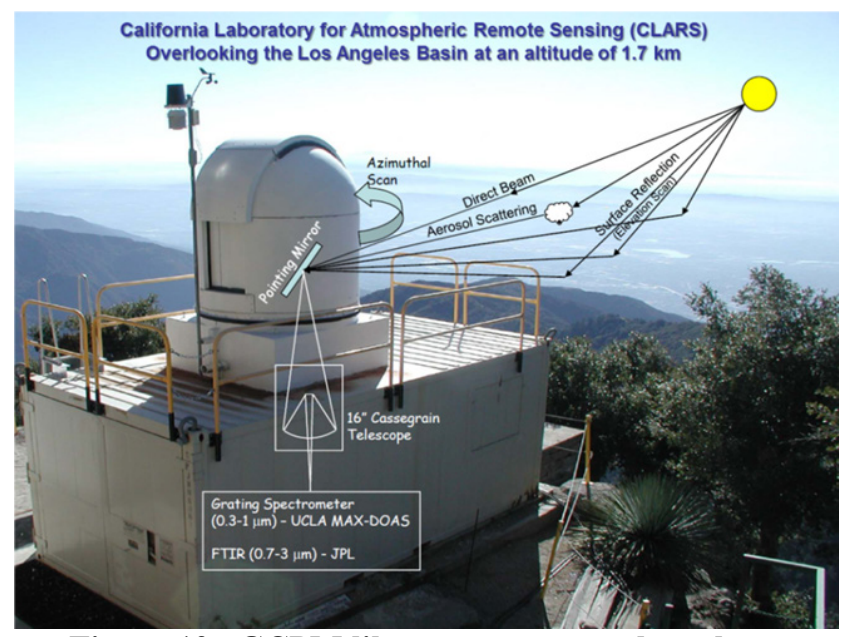

Figure 12. GCPM like measurements have been demonstrated by the CLARS FTS instrument 


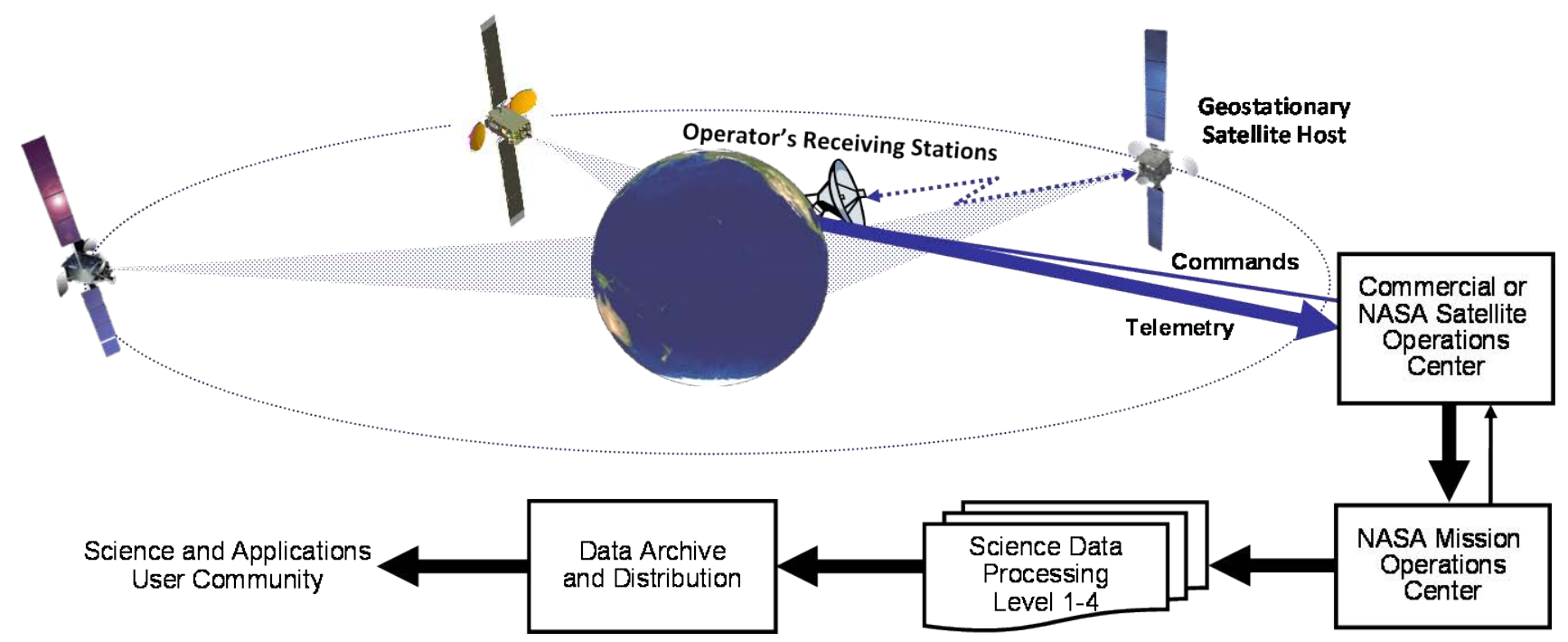

Figure 13. The GCPM hosted payload concept of operations leverages the mission operators existing infrastructure

and archived for distribution to the science and applications communities.

The GeoFTS instrument is designed to be a hosted payload on a commercial communications satellite. The GeoFTS instrument is designed to minimize its impact as part of a shared payload on a commercial satellite mission. It is as small, self-contained, and as independent of the spacecraft as possible. It has a few simple spacecraft interfaces which minimizes the spacecraft modifications needed to host the GeoFTS instrument. This also minimizes the cost and complexity of development, integration and test with the spacecraft, and operations. The GeoFTS instrument design provides excellent compatibility with any GEO spacecraft. Commercial GEO communications satellites have a service life greater than 15 years. At the beginning of life they have significant excess power and telemetry capacity and usually have space on the nadir deck available for secondary hosted payloads like GeoFTS. The GeoFTS instrument is designed for two years of operations with capability for additional years as the situation permits. The GeoFTS instrument will be turned off by the spacecraft owner/operator after years of operation, once the spacecraft performance capabilities have degraded to the point where there is no longer sufficient margin to operate the GeoFTS instrument without interfering with the satellite's primary mission functions.

\section{SUMMARY}

The Geostationary Carbon Process Mapper (GCPM) is an earth science mission to measure key atmospheric trace gases and process tracers related to climate change and human activity. Understanding sources and sinks of $\mathrm{CO}_{2}$ is currently limited by the number of observations per day, as well as uncertainty in vertical transport. The GCPM will greatly improve this situation by making simultaneous high spatial resolution measurements of $\mathrm{CO}_{2}, \mathrm{CH}_{4}, \mathrm{CO}$, and $\mathrm{CF}$ in the near infrared spectral region many times per day from GEO to understand processes which have time scales of minutes to hours. The $\mathrm{CO} 2 / \mathrm{CH} 4 / \mathrm{CO} / \mathrm{CF}$ measurement suite has been specifically selected because their combination provides the information needed to disentangle natural and anthropogenic contributions to atmospheric carbon concentrations and to minimize key uncertainties in the flow of carbon between the atmosphere and surface since they place constraints on both biogenic uptake and release as well as on combustion emissions. Additionally, the combination of high-resolution mapping and high measurement frequency provides quasi-continuous monitoring, which will effectively eliminate atmospheric transport uncertainties from source/sink inversion modeling. The GCPM data set will provide an unprecedented capability to gain new insights and improve the scientific understanding of the sources and sinks of key greenhouse gases, to determine their trends and variability over numerous spatial and temporal scales, to deliver unique insights into carbon weather, and to enable anthropogenic emissions to be distinguished from biogenic sources. A GCPM instrument concept, the GeoFTS, has been developed that can make these measurements from GEO. The advantage of GEO is the ability to continuously stare at a region of the earth, enabling frequent sampling to capture the diurnal variability of biogenic fluxes and anthropogenic emissions from city to continental scales. GCPM will significantly expand NASA's satellite observation capability for mapping carbon cycle process details. Two years of operations as a secondary hosted payload on a commercial communications satellite mission will affordable advance the understanding of observed carbon cycle variability and improve future projections of the carbon cycle and climate.

\section{ACKNOWLEDGMENTS}

The research described in this publication was carried out at the Jet Propulsion Laboratory, California Institute of Technology under a contract with the National Aeronautics and Space Administration. Copyright 2012, California Institute of Technology. Government sponsorship acknowledged. 


\section{REFERENCES}

[1] National Aeronautics and Space Administration 2010 Science Plan for NASA's Science Mission Directorate

[2] “A U.S. Carbon Cycle Science Plan," A report of the University Corporation for Atmospheric Research supported by NASA, DOE, USDA, USGS, NOAA, NSF, and NIST

[3] Palmer, P. I., P. Suntharalingam, D. B. A. Jones, D. J. Jacob, D. G. Streets, Q. Fu, S. A. Vay, and G. W. Sachse (2006), Using $\mathrm{CO}_{2}: \mathrm{CO}$ correlations to improve inverse analyses of carbon fluxes, J. Geophys. Res., 111, D12318, doi:10.1029/2005JD006697.

[4] Andreae, M. O., Merlet, P., Emission of trace gases and aerosols from biomass burning, Global Biogeochemical Cycles, Vol. 15, No. 4, Pages 955-966, 2001.

[5] Frankenberg, C., J. Fisher, J. Worden, G. Badgley, S. Saatchi, J.-E. Lee, G. Toon, A. Butz, M. Jung, A. Kuze, and T. Yokota (2011b), New global observations of the terrestrial carbon cycle from GOSAT: Patterns of plant fluorescence with gross primary productivity, Geophysical Research Letters, 38(17), L17,706.

[6] Frankenberg, C., A. Butz, and G. C. Toon (2011a), Disentangling chlorophyll fluorescence from atmospheric scattering effects in $\mathrm{O}_{2}$ A-band spectra of reflected sunlight, Geophysical Research Letters, 38, L03,801, doi:10.1029/2010GL045896.

[7] Wind speed data from NOAA: (http://lwf.ncdc.noaa.gov/oa/climate/online/ccd/avgwind. html)]

[8] Cohen, B. (2004), Urban Growth in Developing Countries: A Review of Current Trends and a Caution Regarding Existing Forecasts, World Development, 32, 23-51.

[9] Ciais et al., (2010) Modeling atmospheric transport of $\mathrm{CO}_{2}$ at High Resolution to estimate the potentialities of spaceborne observation to monitor anthropogenic emissions, GC41G-09, presented at 2010 Fall Meeting, AGU, San Francisco, Calif., 13-17 Dec. 2010

[10] Beer, C., M. Reichstein, E. Tomelleri, P. Ciais, M. Jung, N. Carvalhais, C. Rödenbeck, M. A. Arain, D. Baldocchi, G. B. Bonan, A. Bondeau, A. Cescatti, G. Lasslop, A. Lindroth, M. Lomas, S. Luyssaert, H. Margolis, K. W. Oleson, O. Roupsard, E. Veendendaal, N. Viovy, C. Williams, F. I. Woodward, and D. Papale (2010), Terrestrial gross carbon dioxide uptake: Global distribution and covariation with climate, Science, 329, 834-838

[11] M. Zhao, S. W. Running, "Drought-Induced Reduction in Global Terrestrial Net Primary Production from 2000 through 2009," Science 329, 940 (2010).
[12] Baldocchi, D. (2008), 'Breathing' of the terrestrial biosphere: lessons learned from a global network of carbon dioxide flux measurement systems, Australian Journal of Botany, 56, 1-26.

[13] Forster, P., et al. (2007), Changes in atmospheric constituents and in radiative forcing, in Climate Change 2007: The Physical Science Basis. Working Group I Report, edited by S. Solomon et al., pp. 131-234, Cambridge Univ. Press, New York.

[14] Frankenberg, C., I. Aben, P. Bergamaschi, E. J. Dlugokencky, R. van Hees, S. Houweling, P. van der Meer, R. Snel, and P. Tol (2011), Global columnaveraged methane mixing ratios from 2003 to 2009 as derived from SCIAMACHY: Trends and variability, J. Geophys. Res., 116, D04302, doi:10.1029/2010JD014849, 2011

[15] Krause, G., and E. Weis (1991), Chlorophyll fluorescence and photosynthesis: The basics, Annual Review Plant Physiological, Plant Molecular Biology, 42, 313-349.

[16] Baker, N. R. (2008), Chlorophyll fluorescence: a probe of photosynthesis in vivo, Annual Review of Plant Biology, 59 (1), 89-113.

[17] Candidate Earth Explorer Mission: flex - fluorescence explorer, Report for Assessment, November 2008, SP-1313/4

[18] Genty, B., J.-M. Briantais, and N. R. Baker (1989), The relationship between the quantum yield of photosynthetic electron transport and quenching of chlorophyll fluorescence, Biochimica et Biophysica Acta, 990, 87-92.

[19] Moya, I., L. Camenen, S. Evain, Y. Goulas, Z. G. Cerovic, G. Latouche, J. Flexas, and A. Ounis (2004), A new instrument for passive remote sensing 1 . Measurements of sunlight-induced chlorophyll fluorescence, Remote Sensing of Environment, 91, 186197

[20] Corp, L. A., E. M. Middleton, J. E. McMurtrey, P. K. Entcheva Campbell, and L. M. Butcher (2006), Fluorescence sensing techniques for vegetation assessment, Applied Optics, 45(5), 1023-1033.

[21] Joiner, J., Y. Yoshida, A. P. Vasilkov, L. A. Corp, and E. M. Middleton (2011), First observations of global and seasonal terrestrial chlorophyll fluorescence from space, Biogeosciences, 8, 637-651. 
[22] Schwalm, C. R., C. A. Williams, K. Schaefer, R. Anderson, M. A. Arain, I. Baker, A. Barr, T. A. Black, G. Chen, J. M. Chen, P. Ciais, K. J. Davis, A. Desai, M. Dietze, D. Dragoni, M. L. Fischer, L. B. Flanagan, R. Grant, L. Gu, D. Hollinger, R. C. Izaurralde, C. Kucharik, P. Lafleur, B. E. Law, L. Li, Z. Li, S. Liu, E. Lokupitiya, Y. Luo, S. Ma, H. Margolis, R. Matamala, H. McCaughey, R. K. Monson, W. C. Oechel, C. Peng, B. Poulter, D. T. Price, D. M. Riciutto, W. Riley, A. K. Sahoo, M. Sprintsin, J. Sun, H. Tian, C. Tonitto, H. Verbeeck, and S. B. Verma (2010), A model-data intercomparison of $\mathrm{CO} 2$ exchange across North America: Results from the North American Carbon Program site synthesis, Journal of Geophysical Research, 115, G00H05.

[23] Friedlingstein, P., P. Cox, R. Betts, L. Bopp, W. von Bloh, V. Brovkin, P. Cadule, S. Doney, M. Eby, I. Fung, G. Bala, J. John, C. Jones, F. Joos, T. Kato, M. Kawamiya, W. Knorr, K. Lindsay, H. D. Matthews, T. Raddatz, P. Rayner, C. Reick, E. Roeckner, K. G. Schnitzler, R. Schnur, K. Strassmann, A. J. Weaver, C. Yoshikawa, and N. Zeng (2006), Climate-carbon cycle feedback analysis: Results from the C4MIP model intercomparison, Journal of Climate, 19(14), 3337-3353.

[24] Wang, H., Jacob, D. J., Kopacz, M., Jones, D. B. A., Suntharalingam, P., Fisher, J. A., Nassar, R., Pawson, S., and Nielsen, J. E.: Error correlation between $\mathrm{CO} 2$ and $\mathrm{CO}$ as constraint for $\mathrm{CO} 2$ flux inversions using satellite data, Atmos. Chem. Phys., 9, 7313-7323, doi:10.5194/acp-97313-2009, 2009.

[25] H. M. Worden, Y. Cheng, G. Pfister, G. Carmichael, M. N. Deeter, D. P. Edwards, J. C. Gille, Q. Zhang, and D. G. Streets. (2010), "Comparison of near-surface CO from multispectral measurements from MOPITT with WRFChem simulations using emissions inventory for the Beijing 2008 Olympics”. AGU Fall Meeting.

[26] Buchwitz, M., de Beek, R., Burrows, J. P., Bovensmann, H., Warneke, T., Notholt, J., Meirink, J. F., Goede, A. P. H., Bergamaschi, P., K" orner, S., Heimann, M., Muller, J. F., and Schulz, A., "Atmospheric methane and carbon dioxide from SCIAMACHY satellite data: initial comparison with chemistry and transport models," Atmos. Chem. Phys. Discuss., 4, 7217-7279, 2004

[27] Kuang, Z., Margolis, J., Toon, G., Crisp, D., and Yung, Y., "Spaceborne measurements of atmospheric $\mathrm{CO}_{2}$ by high-resolution NIR spectrometry of reflected sunlight: An introductory study, Geophys. Res. Lett., 29 (15), doi:10.1029/2001GL014298, 2002.

[28] Butz, A., O. P. Hasekamp, C. Frankenberg, J. Vidot, and I. Aben (2010), $\mathrm{CH}_{4}$ retrievals from space-based solar backscatter measurements: Performance evaluation against simulated aerosol and cirrus loaded scenes, J. Geophys. Res., 115, D24302, doi:10.1029/2010JD014514.
[29] O'Dell, C. W., Connor, B., Bösch, H., O'Brien, D., Frankenberg, C., Castano, R., Christi, M., Eldering, D., Fisher, B., Gunson, M., McDuffie, J., Miller, C. E., Natraj, V., Oyafuso, F., Polonsky, I., Smyth, M., Taylor, T., Toon, G. C., Wennberg, P. O., and Wunch, D.: The ACOS CO2 retrieval algorithm - Part 1: Description and validation against synthetic observations, Atmos. Meas. Tech., 5, 99-121, doi:10.5194/amt-5-99-2012, 2012.

[30] Dubuisson, P., Borde, R., Schmechtig, C., and Santer, R., "Surface pressure estimates from satellite data in the Oxygen A-band: Applications to the MOS sensor over land,” J. Geophys., Res., 106(D21), 27 277-27 286, 2001.

[31] David Crisp, "Measuring CO2 from Space: The NASA Orbiting Carbon Observatory-2," Proceedings of the 61st IAC (International Astronautical Congress), Prague, Czech Republic, Sept. 27-Oct. 1, 2010, IAC-10.B1.6.2

[32] J. M. Krijger, M. vanWeele, I. Aben1, and R. Frey, The effect of sensor resolution on the number of cloud-free observations from space, Atmos. Chem. Phys., 7, 28812891, 2007

[33] Baker, D. F., et al. (2006), TransCom 3 inversion intercomparison: Impact of transport model errors on the interannual variability of regional CO2 fluxes, 1988 2003, Global Biogeochem. Cycles, 20, GB1002, doi:10.1029/2004GB002439.

[34] Key, R., Sander, S., Annmarie L. Eldering, David M. Rider, Jean-Francois L. Blavier, Dmitriy L. Bekker, YenHung $\mathrm{Wu}$, Geostationary Fourier Transform Spectrometer (GeoFTS), IEEE, vol., no., pp.1-15, 5-12 March 2012.

[35] M. R. Gunson, M. M. Abbas, M. C. Abrams, M. Allen, L. R. Brown, T. L. Brown, A. Y. Chang, A. Goldman, F. W. Irion, L. L. Lowes, E. Mahieu, G. L. Manney,1 H. A. Michelsen, M. J. Newchurch, C. P. Rinsland, R. J. Salawitch, G. P. Stiller, G. C. Toon, Y. L. Yung, and R. Zander, "The Atmospheric Trace Molecule Spectroscopy (ATMOS) experiment: Deployment on the ATLAS Space Shuttle missions", Geophys. Res. Lett., 23, 2333-2336, 1996

[36] Beer, R., T.A. Glavich and D.M. Rider, "Tropospheric Emission Spectrometer for the Earth Observing System AURA satellite", Appl. Opt., 40, 2356-2367 (2001).

[37] H. Bloom, "The Cross-Track Infrared Sounder (CrIS): A sensor for operational meterological remote sensing," in Optical Remote Sensing, A. Sawchuk, ed., Vol. 52 of OSA Trends in Optics and Photonics (Optical Society of America, 2001), paper JTuB1.

[38] T Hamazaki, T., Kaneko, Y., Kuze, A., and Kondo, K.: Fourier transform spectrometer for greenhouse gases observing satellite (GOSAT), in: Proceedings of SPIE, vol. 5659, p. 73, 2005. doi: 10.1117/12.581198 
[39] Cageao, R. P.;Blavier, J.-F.;McGuire, J. P.;Jiang, Y.;Nemtchinov, V.;Mills, F. P.; Sander, S. P. HighResolution Fourier-Transform Ultraviolet-Visible Spectrometer for the Measurement of Atmospheric Trace Species: Application to OH, Appl. Opt. 2001, 40, 2024.

[40] D. Willems, T. Benschop, W. v. d. Groep, J. Mullié, H. v. d. Weijden and M. Tops, "Update on Thales flexure bearing coolers and drive electronics", Proc. SPIE 7298, 729815 (2009); doi:10.1117/12.818737

[41] D. Rider et al,. Fast Imaging Detector Readout Circuits with In-Pixel ADCs for Fourier Transform Imaging Spectrometers, NASA Earth Science Technology Forum, June 2011.

[42] Little, A., Estes, R., Neil, D., Rosenbaum, D., Abedin, N., (1998), "Geostationary Tropospheric Pollution Satellite (Geo Tropsat)", NASA Langley Research Center System Study Report, Version 1.3

[43] Andraschko, M.; Antol, J.; Horan, S.; Neil, D.; "Commercially hosted government payloads: Lessons from recent programs," Aerospace Conference, 2011 IEEE , vol., no., pp.1-15, 5-12 March 2011, doi: 10.1109/AERO.2011.5747491

[44] Joseph Simonds, Jie Zhu Jacquot, Charles Kersten, Patricia Lew, and George Sullivan, "Lessons Learned from Hosting an Infrared Payload on a Communications Satellite," 2010 IEEE Aerospace Conference, March 6-13, 2010 .

[45] "NASA to Demonstrate Communications Via Laser Beam," http://www.nasa.gov/topics/technology/features/lasercomm.html

[46] NOAA, U.S. Department of Commerce, Hosted Payloads http://www.space.commerce.gov/general/commercialpu $\underline{\text { rchase/hostedpayloads.shtml }}$

[47] Futron Corporation, "Hosted Payload Guidebook," Bethesda, MD, August 2010.

[48] Hosted Payload Alliance, http:/hostedpayloadalliance.org/

[49] Ken Faller, Alfred Tadros; The Business of Hosted Payloads, 28th AIAA International Communications Satellite Systems Conference 2010, (ICSSC 2010), Anaheim, California, USA, 27 - 30 September 2010

[50] Phillip C. Kalmanson, Carl Schueler, Michael Do and Quang Lam, "A standardized interface and accommodation methodology for commercially hosted payloads on the StarBus", Proc. SPIE 7087, 70870R (2008); doi:10.1117/12.801064 


\section{BIOGRAPHIES}

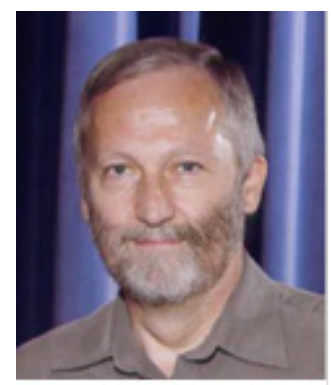

Richard Key earned his B.S. and M.S. degrees in Mechanical Engineering from Purdue University in 1978. He has been with JPL for over 33 years where he has managed the Spacecraft Technology Program, the Large Optical Systems Technology Program and numerous other tasks and programs. He is currently a space mission architect in the Mission and Systems Division at JPL and has worked on designs for flagship planetary missions, astrophysics missions, and Earth science missions. He is the JPL study lead for the NASA Geostationary Coastal and Air Pollution Events (GEOCAPE) Mission and the manager of the Panchromatic Fourier Transform Spectrometer (PanFTS) instrument development task.

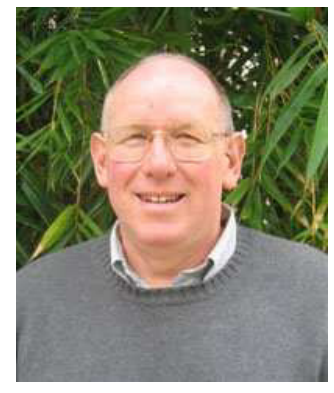

Dr. Stanley Sander received a B.A. degree in Physics from Pomona College (1974), and M.S. (1975) and Ph.D. (1980) degrees in Environmental Engineering Science from Caltech. He is a senior research scientist and supervisor of the Lab Studies and Modeling Group at JPL. He is the Principal Investigator of several atmospheric science investigations and remote sensing instrumentation developments. His interests include photochemistry and kinetics studies of atmospheric processes in Earth and planetary atmospheres, remote sensing of atmospheric composition, and development of advanced instrumentation for atmospheric remote sensing.

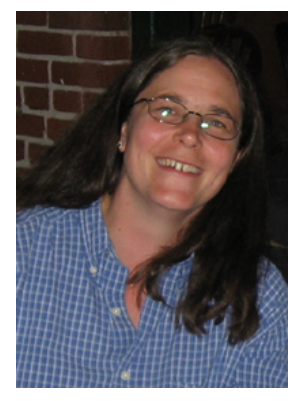

Dr. Annmarie Eldering received a Ph.D. in Environmental Engineering Science from Caltech in 1994 and has been at JPL since 1999, serving in the AIRS group, TES group, and as a section manager, previous to joining the OCO-2 project. She provides dynamic technical leadership to both teams for the extraction of information about clouds, aerosols, and trace gases in the Earth's atmosphere. She is the Principal Investigator or a co-Investigator on a number of competitively awarded research tasks, and has worked on a number of mission concepts. Recently, she has been an active member of the GEO-CAPE Science Working Group, and served as the TES Deputy PI and then PI. She is Currently the Deputy Project Scientist for the Orbiting Carbon Observatory-2.

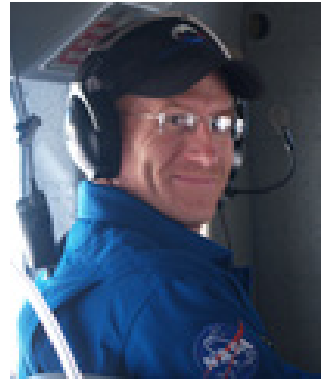

Dr. Charles Miller received a B.S. in Chemistry and History from Duke University, and a Ph.D. in Chemical Physics from the University of California, Berkeley. He is a Project Scientist with the JPL Earth Atmospheric Science Section. He is Principal Investigator of the CARVE investigation, a member of the Orbiting Carbon Observatory (OCO-2) Science Team, and a member of the GOSAT RA Science Team; he was Deputy Principal Investigator of the original OCO mission. He conducts research in carbon cycle science, atmospheric photochemistry, molecular spectroscopy, and developing new solutions for satellite remote sensing of greenhouse gases.

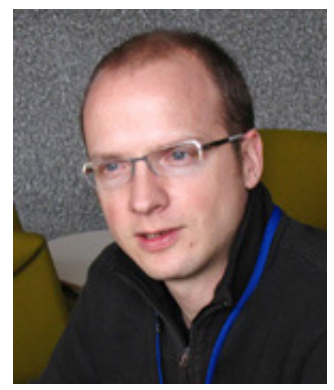

Dr. Christian Frankenberg received his $P h D$ from the Institute of Environmental Physics in Heidelberg in 2005. He was a postdoctoral scholar at the Netherlands Institute for Space Research, where he published extensively on remote sensing data from SCIAMACHY, specifically $\mathrm{CO} 2, \mathrm{CH} 4$, and HDO. He is now a research scientist at the JPL, where he is a member of the OCO-2 science and algorithm teams.

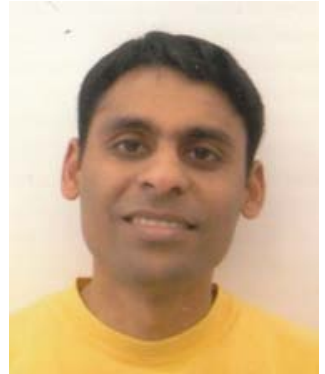

Dr. Vijay Natraj received his B.S. M.S. degrees in Chemical Engineering from the National University of Singapore (NUS), Singapore, in 1998 and 2002, respectively, and a Ph.D. degree in Chemical Engineering from Caltech in 2008. His master thesis project was on the flow behavior of polyelectrolytes. His Ph.D. dissertation was on radiative transfer modeling for $\mathrm{CO}_{2}$ retrievals from space. He worked as a research engineer in the Department of Chemical Engineering at NUS from 1998 to 2001. He also worked as a Researcher in the Department of Planetary Sciences at Caltech, where he still holds a visiting position. He joined JPL as a Scientist in February 2010. His research interests are in the areas of polarization, aerosol and cloud modeling, fast radiative transfer computations, and information theoretical analysis. 


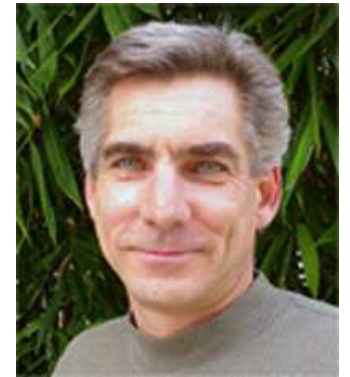

Dr. David Rider came to the Jet Propulsion Laboratory in 1983 after completing a Ph.D. in physical chemistry at Michigan State University and Post Doctoral research at Stanford University. At JPL he has worked on the development of wide variety of atmospheric remote sensing instrumentation for both planetary and Earth missions. Most recently he was Instrument Scientist for the Tropospheric Emission Spectrometer (TES) on NASA's Aura Earth Observing Spacecraft and a member of the Orbiting Carbon Observatory (OCO) science team.

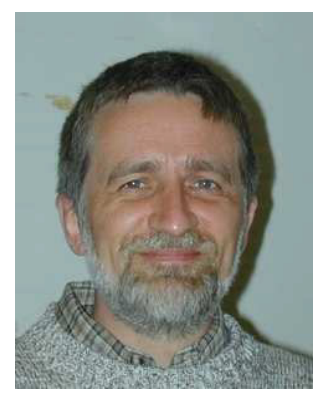

Dr. Jean-Francois Blavier first joined JPL in 1985 as a contractor from Ball Aerospace and participated in the MkIV FTIR campaigns to study the Antarctic ozone loss. He was hired by JPL in 1990 as member of the Atmospheric Observation group. His research centers on the design of Fourier Transform Spectrometers to measure the composition of Earth and planetary atmospheres from a variety of platforms (spacecraft, aircraft, balloon, ground). He obtained his License (1983) and Doctorate (1998) in Physics from the University of Liege, Belgium.

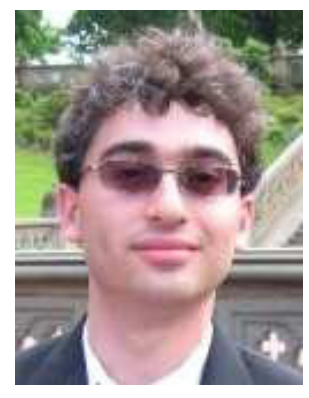

Dmitriy Bekker received his B.S. and M.S. degrees in Computer Engineering from Rochester Institute of Technology in 2007. In 2008 he joined JPL as a Staff Engineer in the Instrument Flight and GSE Software group in the Instrument Software and Science Data Systems Section. He is currently working on FPGA based data acquisition and processing designs for multiple prototype science instruments. His areas of interests include FPGAs, embedded systems, digital signal processing, and system architecture.

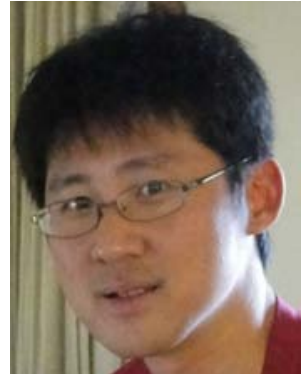

Yen-Hung (James) Wu received a B.S. in Mechanical Engineering from University of Massachusetts in 1999, and a M.S. in Optical Engineering from University of Arizona in 2007. He joined JPL in 2007 where he is a Staff Engineer in Interferometry and Advanced Optical System Section. He is working on a number of advanced remote sensing instrument designs for earth science, astrophysics, and planetary missions. His areas of interest include optical engineering and optomechanical design relating to space-borne instruments. 